\title{
Older Medicare Beneficiaries Frequently Continue Medications with Limited Benefit Following Hospice Admission
}

\author{
Patrick M. Zueger, PharmD, PhD ${ }^{7}$, Holly M. Holmes, MD, $M S^{2}$, \\ Gregory S. Calip, PharmD, MPH, PhD ${ }^{1,3,4}$, Dima M. Qato, PharmD, MPH, $P h D^{1,3}$,
} A. Simon Pickard, $P h D^{7,3}$, and Todd A. Lee, PharmD, $P h D^{7,3}$

\begin{abstract}
'Department of Pharmacy Systems, Outcomes and Policy, University of Illinois at Chicago, Chicago, IL, USA; '2Division of Geriatric and Palliative Medicine, UTHealth McGovern Medical School, Houston, TX, USA; ${ }^{3}$ Center for Pharmacoepidemiology and Pharmacoeconomic Research, University of Illinois at Chicago, Chicago, IL, USA; ${ }^{4}$ Division of Public Health Sciences, Epidemiology Program, Fred Hutchinson Cancer Research Center, Seattle, WA, USA.
\end{abstract}

BACKGROUND: The use of medications not relieving symptoms or maximizing quality of life should be minimized following hospice enrollment.

OBJECTIVE: To evaluate the frequency of and predictive factors for continuation of medications with limited benefit after hospice admission among those admitted for cancer- and non-cancer-related causes.

DESIGN: Cohort study using the Surveillance, Epidemiology and End Results-Medicare linked database.

PATIENTS: Medicare Part D-enrolled beneficiaries 66 years and older who were admitted to and died under hospice care between January 1, 2008, and December 31, $2013(N=70,035)$.

MAIN MEASURES: Patients were followed from hospice enrollment through death for Part D dispensing of limited benefit medications (LBMs) they had used in the 6 months prior to hospice admission, including antihyperlipidemics, anti-hypertensives, oral anti-diabetics, anti-platelets, anti-dementia medications, antiosteoporotic medications, and proton pump inhibitors. The proportion of patients continuing an LBM after hospice admission was evaluated. Adjusted relative risks (RRs) were estimated for factors associated with LBM continuation.

KEY RESULTS: Overall, 29.8\% and 30.5\% of patients admitted to hospice for a cancer- and non-cancerrelated cause, respectively, continued at least one LBM after hospice admission. Anti-dementia medications were continued most frequently (29.3\%) while antiosteoporotic medications were continued least often (14.1\%). Compared to home hospice, LBM continuation was greater in hospice patients residing in skilled nursing (RR 1.25, 95\% CI 1.20-1.29), non-skilled nursing (RR 1.29, 95\% CI 1.25-1.32), and assisted living facilities (RR 1.28, 95\% CI 1.24-1.32). Patients with hospice stays $\geq 180$ days were more likely to continue at least one LBM

Electronic supplementary material The online version of this article (https://doi.org/10.1007/s11606-019-05152-x) contains supplementary material, which is available to authorized users.

Received May 28, 2018

Revised February 6, 2019

Accepted May 1, 2019

Published online July 25, 2019 compared to those with stays of 1 week or less (RR 13.11, 95\% CI 12.25-14.02).

CONCLUSIONS: A substantial proportion of Medicare hospice beneficiaries continued to receive LBMs following hospice enrollment. Providers should evaluate the necessity of continuing non-palliative medications at the end of life through a careful, patient-centric consideration of their potential risks and benefits.

KEY WORDS: hospice; inappropriate medication use; deprescribing; Medicare Part D; end-of-life care.

J Gen Intern Med 34(10):2029-37

DOI: $10.1007 / \mathrm{s} 11606-019-05152-\mathrm{x}$

(c) Society of General Internal Medicine 2019

\section{INTRODUCTION}

In 2015, 46\% of all Medicare decedents were enrolled in hospice care at the time of death. ${ }^{1}$ Medicare's hospice benefit pays for enrollees' hospice-related care, including medications for palliative treatment of the terminal illness and related conditions, through Medicare Part A. Medications unrelated to the palliation of the patient's terminal illness may still be obtained through the Medicare Part D Prescription Drug Benefit for those with an active Part D plan. ${ }^{2}$

As the central purpose of hospice is to provide comfort care and support measures, medications which do not provide symptom relief or help to maximize quality of life may be unnecessary. Patients receiving hospice care are prescribed, on average, greater than 10 unique medications during their stay, including medications which are unlikely to have a palliative focus. ${ }^{3-5}$ The number of medications patients are prescribed as they approach the end of life has been shown to vary according to their terminal illness and associated disease trajectory, though it is unclear whether this variation is driven by changes in palliative medication prescribing only or whether differences in discontinuation of non-palliative medications also exist. ${ }^{6,7}$

In addition to limited effectiveness, continuation of these potentially unnecessary medications may increase the risk of 
medication side effects and drug-drug interactions, particularly given the high degree of polypharmacy often present in older adults as well as the physiological changes which occur as individuals approach the end of life. ${ }^{8-11}$ Other unintended consequences such as increased patient and healthcare system costs and burden on caregivers may also result. ${ }^{12-15}$ A number of barriers to routine deprescribing in the setting of limited life expectancy have been identified to date, including a reluctance among clinicians to discuss de-escalation of therapy, clinical inertia, refusal by patients and family members to stop medications, and lack of clinical consensus on what constitutes inappropriate medication use in the terminally ill. ${ }^{10,} 12,16-22$

We have previously reported the overall frequency of medication receipt, including potentially non-palliative drugs, through the Medicare Part D benefit in patients admitted to hospice. ${ }^{23}$ However, the continued use of limited benefit medications after hospice admission in patients with a history of use prior to admission has not been quantified nor well characterized. It is unclear whether post-admission continuation may vary according to medication class, hospice admission diagnosis, or other patient and clinical factors. The goal of this research was to describe the prevalence of continuing medications with limited benefit after hospice admission among those with pre-hospice admission use, and identify factors associated with continuation in Medicare beneficiaries admitted to hospice for cancer- and non-cancer-related causes.

\section{METHODS}

\section{Data Source and Study Population}

This study used the nationally representative Surveillance, Epidemiology and End Results (SEER)-Medicare linked database and a random 5\% non-cancer sample of Medicare beneficiaries residing in the SEER registry regions. Comprehensive, de-identified administrative claims were available for fee-for-service Medicare beneficiaries from January 1, 2007, to December 31, 2013. Claims contained data on sociodemographic characteristics, Medicare enrollment, healthcare utilization, diagnoses and procedures, vital status, and Medicare Part D prescription dispensing. The Medicare hospice enrollment file was used to identify individuals who enrolled and subsequently died in hospice between January 1 , 2008, and December 31, 2013.

Patients aged less than 66 years at hospice admission and those not continuously enrolled in Medicare Parts A, B, and D from 1 year prior to hospice entry through the date of death were excluded. Patients with any enrollment in a Medicare Advantage plan were also excluded. Patients were required to have at least one Part D claim in the year prior to admission and no hospice enrollment gaps (i.e., discharges) lasting greater than 30 days after initial hospice admission.

The primary International Classification of Diseases, Ninth Revision (ICD-9) diagnostic code on the initial hospice claim was used to classify patients as having an admission for a cancer or non-cancer diagnosis (Online Supplementary Appendix). SEER registry patients included in the cancer admission cohort were those admitted to hospice with a primary diagnosis of lung, colorectal, breast, pancreatic cancer, or lymphoma, which have been reported as the five most prevalent cancer-related hospice admission diagnoses among Medicare beneficiaries. ${ }^{24} \mathrm{~A}$ unique patient identifier allowed for linkage of the SEER cancer cases with their respective Medicare claims. Patients admitted to hospice for a non-cancer diagnosis were identified from the random $5 \%$ non-cancer sample in addition to those in the SEER registry who ultimately entered hospice with a non-cancer-related primary admission diagnosis, despite being diagnosed with cancer in the past.

\section{Medications with Limited Benefit Definition}

Medication classes considered to be of potentially limited benefit in the end-of-life population were identified via literature review, which included primary research studies, review articles, and expert opinion pieces. ${ }^{16,} 18,25-35$ Antihyperlipidemics, anti-hypertensives, oral antidiabetics, antiplatelets, anti-dementia medications, anti-osteoporotic medications, and proton pump inhibitors were included, with some disease-specific exceptions. Based on the aforementioned literature and expert opinion, drug classes were excluded from the analysis at the patient level if a diagnosis was present (via ICD-9 codes on two outpatient claims or one inpatient admission) in the year prior to hospice admission for a condition where the medication may provide a symptomatic benefit or decrease the short-term (e.g., $<1$ year) risk of major adverse events (Table 1). Medication classes that were entirely available over-the-counter during the study period (e.g., H2 receptor antagonists) were excluded as they are not reliably captured via Medicare Part D claims. While not intended to be definitive or comprehensive, the selected medication classes are characterized by a general lack of utility in the palliation of terminal illness symptoms or in optimizing quality of life near the end of life.

\section{Limited Benefit Medication Use}

Baseline limited benefit medication use was measured in the 6 months prior to hospice admission. Patients were considered active pre-hospice admission users of a particular drug or therapeutic class if they had two or more Part D claims for any days' supply on different days for the class of interest or one Part D claim with a days' supply of at least 90 days. Patients not meeting these criteria for at least one limited benefit medication were excluded (Fig. 1).

\section{Outcomes}

The primary outcome was continuation of at least one limited benefit medication between the date of hospice admission and date of death. Pre-admission users of a particular drug class 
Table 1 Medication Classes Identified as Being of Limited Benefit in Patients Receiving Hospice Care and Criteria for Exclusion from the Continuation Analysis*

\begin{tabular}{|c|c|c|}
\hline Therapeutic class & Associated drug classes & Patient-specific exclusions \\
\hline Anti-hypertensive & $\begin{array}{l}\text { Thiazide diuretics } \\
\text { Other non-loop diuretics } \\
\text { ACE inhibitors } \\
\text { ARBs } \\
\text { DHP CCBs } \\
\text { Non-DHP CCBs } \\
\text { Beta-blockers } \\
\text { Alpha-blockers } \\
\text { Centrally acting agents } \\
\text { Vasodilators } \\
\text { Direct renin inhibitors }\end{array}$ & $\begin{array}{l}\text { i. Diuretics, beta-adrenergic antagonists, ACE inhibitors, } \\
\text { ARBs, and hydralazine (in combination with nitrates) } \\
\text { excluded when used for congestive heart failure } \\
\text { ii. Beta-adrenergic antagonists and CCBs excluded } \\
\text { when used for angina pectoris } \\
\text { iii. Non-DHP CCBs and beta-adrenergic antagonists } \\
\text { excluded when used for atrial fibrillation/flutter } \\
\text { iv. Beta-adrenergic antagonists, ACE inhibitors, and ARBs } \\
\text { excluded when used after recent myocardial infarction }{ }^{\dagger}\end{array}$ \\
\hline Oral antidiabetic & $\begin{array}{l}\text { Biguanides } \\
\text { Sulfonylureas } \\
\text { Dipeptidyl peptidase-4 inhibitors } \\
\text { Meglitinides } \\
\text { Alpha glucosidase inhibitors } \\
\text { Thiazolidinediones }\end{array}$ & \\
\hline \multirow[t]{2}{*}{ Anti-platelet } & $\begin{array}{l}\mathrm{P}^{2} \mathrm{Y}_{12} \text { inhibitors } \\
\text { Aspirin-dipyridamole }\end{array}$ & $\begin{array}{l}\text { i. } \mathrm{P}_{2} \mathrm{Y}_{12} \text { inhibitors excluded when used after recent } \\
\text { myocardial infarction or ischemic stroke } \\
\text { ii. Aspirin-dipyridamole excluded when used after } \\
\text { recent ischemic stroke }\end{array}$ \\
\hline & Proton pump inhibitors & \\
\hline
\end{tabular}

ACE angiotensin-converting enzyme, ARB angiotensin receptor blocker, CCB calcium channel blocker, DHP dihydropyridine, SERM selective estrogen receptor modulators

*identified via published literature ${ }^{16,18,25-35}$ (medication classes and patient-specific exclusions) and expert opinion (patient-specific exclusions only)

'Recent' defined as presence of a primary hospital discharge for the event in the 12 month prior to hospice admission

${ }^{*}$ Includes amiloride and triamterene in combination with hydrochlorothiazide; includes all formulations of spironolactone

with at least one new Part D claim for a medication from the same class on or after the date of hospice admission were considered continuers of the class of medications. Medication class-specific continuation and post-admission continuation of all limited benefit medication classes used in the pre-hospice admission period were assessed.

\section{Statistical Analysis}

Descriptive statistics were used to evaluate baseline characteristics, pre-hospice admission limited benefit medication use, and post-admission continuation overall and stratified by cancer versus non-cancer hospice admission diagnosis. Drug and therapeutic class-specific continuation prevalence for patients admitted to hospice for a cancer versus non-cancer diagnosis were compared using absolute risk differences with $95 \%$ confidence intervals (CIs).

Modified Poisson regression with generalized estimating equations was used to generate adjusted relative risks (RRs) and $95 \%$ CIs for the association between patient factors and the continuation of at least one drug or therapeutic class with limited benefit after hospice admission, accounting for anticipated clustering of responses at the hospice facility level. ${ }^{36,37}$ An exchangeable correlation structure with robust variance estimation was used to allow for valid standard error estimates.
A separate model was fit for each factor of interest. ${ }^{38}$ Fractional polynomials were used to allow for non-linear exposure-outcome relationships. A manual backwards selection approach was used to identify potential confounders using a change in estimate criterion of $5 \%$, as simulations have found the commonly used $10 \%$ change in estimate criterion to be too conservative for large sample sizes. ${ }^{39}$ Age, gender, and race were treated as a priori confounders and forced into all models, regardless of empirical evidence of confounding. All statistical tests were two-sided with $p$ values $<0.05$ considered statistically significant. Analyses were conducted using SAS version 9.4 (SAS Institute Inc., Cary, NC) and STATA 14.0 (StataCorp, College Station, TX). The institutional review board at the University of Illinois at Chicago approved this study. Informed consent was not obtained as this study was determined by the institutional review board to not constitute human subjects research.

\section{RESULTS}

Of 88,957 patients initially identified, 70,035 patients (78.7\%) had active use of at least one limited benefit medication prior to hospice admission; 44,218 (63.1\%) patients were admitted to hospice for cancer and 25,817 (36.9\%) patients were 


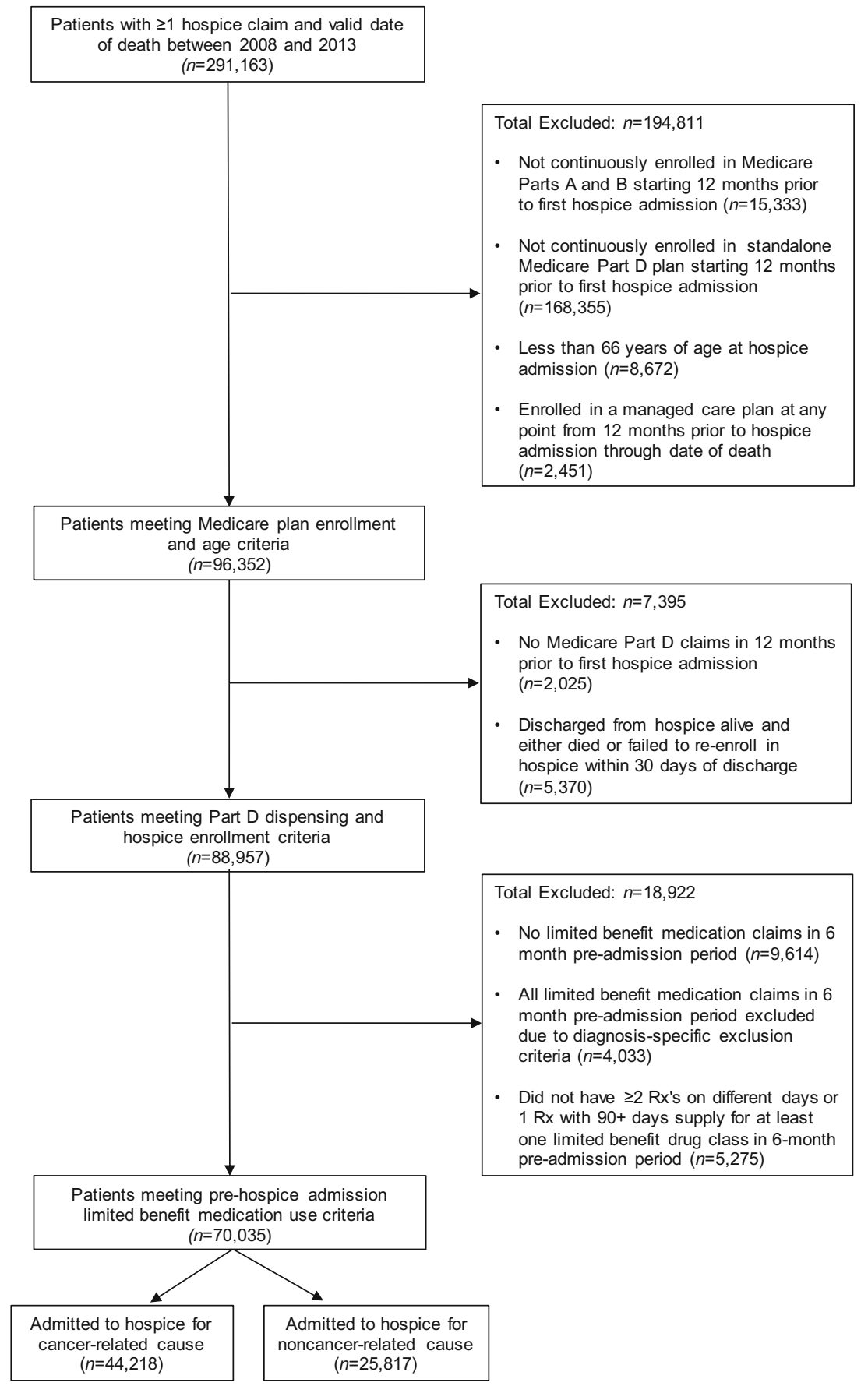

Figure 1 Patient flow diagram

admitted for a non-cancer diagnosis (Fig. 1). Most patients were white $(85.2 \%)$ and female $(67.3 \%)$ (Table 2$)$. The median (interquartile range [IQR]) hospice length of stay was 15 (548) days, $65 \%$ of patients had hospice stays of less than 30 days, and the mean (standard deviation [SD]) number of unique medications used through the Part $\mathrm{D}$ benefit prior to hospice admission was 15.7 (7.0). Compared to patients admitted for a non-cancer diagnosis, patients admitted to hospice for cancer were younger (mean (SD), 79.2 (7.7) years vs. 85.5 (7.8) years, $p<0.001$ ), were more likely to be admitted to hospice in a private home $(68.7 \%$ vs. $38.2 \%, p<0.001)$, and had fewer very short ( $\leq 7$ days, $29.9 \%$ vs. $39.1 \%, p<0.001$ ) or very long ( $\geq 180$ days, $4.9 \%$ vs. $9.2 \%, p<0.001)$ hospice stays (Table 2). The most common admission diagnoses in the noncancer cohort were debility/failure to thrive (22.3\%), dementia $(21.0 \%)$, and heart disease $(16.9 \%)$.

The primary outcome, continuation of at least one limited benefit medication after hospice admission among those with active pre-admission use of at least one of these medications, occurred in $29.8 \%$ of patients admitted for cancer and $30.5 \%$ of patients admitted for a non-cancer diagnosis. For both cancer and non-cancer patients, anti-dementia medications 
Table 2 Demographic and Clinical Characteristics of Study Cohort

\begin{tabular}{|c|c|c|c|}
\hline Characteristic & $\begin{array}{l}\text { All } \\
\text { patients } \\
(n= \\
\mathbf{7 0 , 0 3 5 )}\end{array}$ & $\begin{array}{l}\text { Cancer } \\
(n= \\
44,218)\end{array}$ & $\begin{array}{l}\begin{array}{l}\text { Non- } \\
\text { cancer } \\
(n= \\
\mathbf{2 5 , 8 1 7})\end{array} \\
\end{array}$ \\
\hline Female sex & $67.3 \%$ & $63.5 \%$ & $73.8 \%$ \\
\hline \multicolumn{4}{|l|}{ Age (years) } \\
\hline Mean (SD) & $81.5(8.3)$ & $79.2(7.7)$ & $85.5(7.8)$ \\
\hline $66-69$ & $8.7 \%$ & $12.0 \%$ & $3.2 \%$ \\
\hline $70-74$ & $15.1 \%$ & $19.7 \%$ & $7.2 \%$ \\
\hline $75-79$ & $17.2 \%$ & $20.5 \%$ & $11.4 \%$ \\
\hline $80-84$ & $20.3 \%$ & $21.0 \%$ & $19.1 \%$ \\
\hline $85-89$ & $20.0 \%$ & $16.4 \%$ & $26.0 \%$ \\
\hline$\geq 90$ & $18.8 \%$ & $10.5 \%$ & $33.1 \%$ \\
\hline \multicolumn{4}{|l|}{ Race } \\
\hline White & $85.2 \%$ & $83.8 \%$ & $87.5 \%$ \\
\hline Black & $8.3 \%$ & $8.8 \%$ & $7.5 \%$ \\
\hline Hispanic & $2.0 \%$ & $2.0 \%$ & $1.9 \%$ \\
\hline Asian & $2.9 \%$ & $3.4 \%$ & $1.8 \%$ \\
\hline Other or missing & $1.7 \%$ & $1.9 \%$ & $1.3 \%$ \\
\hline \multicolumn{4}{|l|}{ Geographic region } \\
\hline Midwest & $16.1 \%$ & $15.1 \%$ & $17.8 \%$ \\
\hline Northeast & $20.5 \%$ & $20.6 \%$ & $20.3 \%$ \\
\hline South & $29.0 \%$ & $29.0 \%$ & $29.0 \%$ \\
\hline West & $34.4 \%$ & $35.3 \%$ & $32.8 \%$ \\
\hline \multicolumn{4}{|l|}{ Hospice admission year } \\
\hline 2008 & $16.6 \%$ & $18.2 \%$ & $13.9 \%$ \\
\hline 2009 & $18.0 \%$ & $19.5 \%$ & $15.5 \%$ \\
\hline 2010 & $18.8 \%$ & $20.0 \%$ & $16.9 \%$ \\
\hline 2011 & $19.4 \%$ & $19.8 \%$ & $18.7 \%$ \\
\hline 2012 & $15.4 \%$ & $13.4 \%$ & $18.8 \%$ \\
\hline 2013 & $11.8 \%$ & $9.2 \%$ & $16.3 \%$ \\
\hline \multicolumn{4}{|l|}{ Hospice admission setting } \\
\hline Private home & $57.5 \%$ & $68.7 \%$ & $38.2 \%$ \\
\hline Assisted living facility & $4.4 \%$ & $2.6 \%$ & $7.6 \%$ \\
\hline Non-skilled nursing facility & $12.3 \%$ & $7.8 \%$ & $20.0 \%$ \\
\hline Skilled nursing facility & $8.3 \%$ & $5.8 \%$ & $12.5 \%$ \\
\hline $\begin{array}{l}\text { Inpatient (acute care) } \\
\text { hospital }\end{array}$ & $8.2 \%$ & $6.6 \%$ & $10.8 \%$ \\
\hline Inpatient hospice facility & $8.1 \%$ & $7.3 \%$ & $9.4 \%$ \\
\hline Other or missing & $1.3 \%$ & $1.3 \%$ & $1.4 \%$ \\
\hline \multicolumn{4}{|c|}{ Primary hospice admission diagnosis } \\
\hline Cancer & $63.1 \%$ & $100.0 \%$ & $0 \%$ \\
\hline Debility or failure to thrive & $8.2 \%$ & $0 \%$ & $22.3 \%$ \\
\hline Dementia & $7.8 \%$ & $0 \%$ & $21.0 \%$ \\
\hline Lung disease & $5.1 \%$ & $0 \%$ & $13.8 \%$ \\
\hline Heart disease & $6.2 \%$ & $0 \%$ & $16.9 \%$ \\
\hline Ischemic stroke & $2.0 \%$ & $0 \%$ & $5.4 \%$ \\
\hline Renal disease & $2.2 \%$ & $0 \%$ & $5.9 \%$ \\
\hline Other non-cancer & $5.4 \%$ & $0 \%$ & $14.7 \%$ \\
\hline \multicolumn{4}{|l|}{ Hospice length of stay (days) } \\
\hline Median (IQR) & $15(5-48)$ & $17(6-47)$ & $12(4-50)$ \\
\hline$\leq 7$ & $33.3 \%$ & $29.9 \%$ & $39.1 \%$ \\
\hline $8-14$ & $15.7 \%$ & $16.0 \%$ & $15.2 \%$ \\
\hline $15-29$ & $15.9 \%$ & $17.8 \%$ & $12.7 \%$ \\
\hline $30-89$ & $20.5 \%$ & $23.3 \%$ & $15.6 \%$ \\
\hline $90-179$ & $8.1 \%$ & $8.1 \%$ & $8.0 \%$ \\
\hline$\geq 180$ & $6.5 \%$ & $4.9 \%$ & $9.2 \%$ \\
\hline \multicolumn{4}{|l|}{ Comorbidity } \\
\hline Hypertension & $86.4 \%$ & $85.5 \%$ & $88.0 \%$ \\
\hline Heart failure & $33.5 \%$ & $24.6 \%$ & $48.8 \%$ \\
\hline Diabetes mellitus & $40.9 \%$ & $40.4 \%$ & $41.8 \%$ \\
\hline COPD & $41.7 \%$ & $43.3 \%$ & $39.0 \%$ \\
\hline Recent ischemic stroke & $5.9 \%$ & $3.9 \%$ & $9.5 \%$ \\
\hline $\begin{array}{l}\text { Recent myocardial } \\
\text { infarction }\end{array}$ & $4.6 \%$ & $3.0 \%$ & $7.2 \%$ \\
\hline Coronary atherosclerosis & $36.9 \%$ & $34.0 \%$ & $41.9 \%$ \\
\hline Cardiac dysrhythmia & $43.3 \%$ & $38.2 \%$ & $51.9 \%$ \\
\hline Renal disease & $24.5 \%$ & $19.6 \%$ & $33.0 \%$ \\
\hline Liver disease & $20.2 \%$ & $25.4 \%$ & $11.4 \%$ \\
\hline & & $17.4 \%$ & $35.5 \%$ \\
\hline \multicolumn{4}{|c|}{ Hospitalizations in year prior to admission } \\
\hline 0 & $18.0 \%$ & $17.5 \%$ & $18.9 \%$ \\
\hline 1 & $29.0 \%$ & $29.8 \%$ & $27.8 \%$ \\
\hline 2 & $21.5 \%$ & $22.2 \%$ & $20.2 \%$ \\
\hline 3 or 4 & $21.4 \%$ & $21.4 \%$ & $21.4 \%$ \\
\hline
\end{tabular}

(continued on next page)
Table 2. (continued)

\begin{tabular}{|c|c|c|c|}
\hline Characteristic & $\begin{array}{l}\text { All } \\
\text { patients } \\
(n= \\
\mathbf{7 0 , 0 3 5 )}\end{array}$ & $\begin{array}{l}\text { Cancer } \\
(n= \\
44,218)\end{array}$ & $\begin{array}{l}\begin{array}{l}\text { Non- } \\
\text { cancer } \\
(n= \\
25,817)\end{array} \\
\end{array}$ \\
\hline 5 or $n$ & $10.1 \%$ & $9.1 \%$ & $1.7 \%$ \\
\hline $\begin{array}{l}\text { ICU stay in } 90 \text { days prior to } \\
\text { admission }\end{array}$ & $26.5 \%$ & $23.8 \%$ & $1.2 \%$ \\
\hline $\begin{array}{l}\text { Hospital discharge to } \\
\text { hospice }^{\dagger}\end{array}$ & $43.1 \%$ & $41.7 \%$ & $45.7 \%$ \\
\hline \multicolumn{4}{|c|}{ Number of outpatient clinicians in year prior to admission } \\
\hline Median (IQR) & $5(3-8)$ & $6(4-9)$ & $4(3-7)$ \\
\hline \multicolumn{4}{|c|}{ Unique Part $\mathrm{D}$ medications in year prior to admission } \\
\hline Mean (SD) & $15.7(7.0)$ & $15.8(7.0)$ & $15.5(7.1$ \\
\hline \multicolumn{4}{|c|}{ Limited benefit drug classes used in 6 months prior to admission } \\
\hline Mean (SD) & $2.6(1.5)$ & $2.6(1.5)$ & $2.5(1.5)$ \\
\hline $\begin{array}{l}\text { Part D low-income subsidy } \\
\text { recipient }\end{array}$ & $42.9 \%$ & $39.5 \%$ & $48.7 \%$ \\
\hline
\end{tabular}

$S D$ standard deviation, ICU intensive care unit, IQR interquartile range, COPD chronic obstructive pulmonary disease

$p<0.001$ for all cancer versus non-cancer group comparisons using $t$ tests for continuous variables and Pearson's chi-square tests for categorical variables

${ }^{H}$ Hospital discharge occurring in the 3 days prior to hospice admission ${ }^{7}$ Excludes claims generated in emergency departments, outpatient hospitals, and surgery centers; includes physicians, physician's assistants, and nurse practitioners as clinicians

(33.4\% and $27.3 \%)$ and anti-hypertensives $(26.7 \%$ and $26.0 \%$ ) were the most frequently continued therapeutic classes while anti-osteoporotic medications $(13.2 \%$ and $15.4 \%)$ and anti-hyperlipidemic medications (15.1\% and $19.0 \%)$ were continued least often (Table 3). Compared to admission for a non-cancer diagnosis, patients admitted to hospice for cancer had a lower absolute risk of continuing anti-hyperlipidemic ($3.9 \%$; $95 \% \mathrm{CI},-4.9$ to $-2.9 \%$ ) and anti-osteoporotic medications $(-2.1 \% ; 95 \% \mathrm{CI},-4.0$ to $-0.3 \%)$, but a higher risk of continuing anti-dementia medications $(6.0 \%$; $95 \% \mathrm{CI}, 4.2$ to $7.8 \%$ ) (Table 3).

In adjusted analyses, the likelihood of continuing at least one medication with limited benefit after hospice admission increased with age and was lower for Asian (RR 0.85; 95\% CI, $0.80-0.91$ ) and Hispanic patients (RR $0.88 ; 95 \%$ CI, $0.82-$ 0.94 ) compared to White patients (Table 4). The risk of continuing one or more limited benefit medications was 1.28 (95\% CI, 1.24-1.32) among those in assisted living facilities, 1.29 (95\% CI, 1.25-1.32) among those in non-skilled nursing facilities, and 1.25 (95\% CI, 1.20-1.29) among those in skilled nursing facilities compared to those admitted to hospice in a private home. Conversely, the risk of continuing one or more limited benefit medications was 0.45 (95\% CI, 0.40-0.51) among those in acute care hospitals and 0.46 (95\% CI, 0.40 0.52) among those in inpatient hospice facilities compared to private home admission. By hospice length of stay, the likelihood of receiving at least one limited benefit medication after admission was 2.59 times greater (95\% CI 2.41-2.79) for those with stays of 8-14 days compared to those with stays $\leq 7$ days, increasing to 9.39 (95\% CI 8.80-10.02) and 13.11 (95\% CI 12.25-14.02) for those with hospice stays of 3089 days and 180 or more days, respectively (Table 4). 
Table 3 Pre-hospice Admission Limited Benefit Medication Use and Post-admission Continuation Among Pre-admission Users by Cancer Versus Non-cancer Hospice Admission Diagnosis

\begin{tabular}{|c|c|c|c|c|c|}
\hline & \multicolumn{2}{|c|}{ Pre-hospice admission use } & \multicolumn{2}{|c|}{$\begin{array}{l}\text { Proportion of users continuing } \\
\text { after admission* }\end{array}$} & \multirow{2}{*}{$\begin{array}{l}\text { Risk difference, } \\
\text { cancer versus } \\
\text { non-cancer }\end{array}$} \\
\hline & Cancer $(n=44,218)$ & Non-cancer $(n=25,817)$ & Cancer & Non-cancer & \\
\hline Therapeutic or drug class ${ }^{*}$ & No. (\%) & No. $(\%)$ & No. $(\%)$ & No. $(\%)$ & $\%(95 \% \mathrm{CI})$ \\
\hline Anti-hyperlipidemic & $17,760(40.2 \%)$ & $8799(34.1 \%)$ & $2682(15.1 \%)$ & $1671(19.0 \%)$ & $-3.9(-4.9,-2.9)$ \\
\hline Statin & $16,411(37.1 \%)$ & $7976(30.9 \%)$ & $2457(15.0 \%)$ & $1532(19.2 \%)$ & $-4.2(-5.3,-3.2)$ \\
\hline Anti-hypertensive & $30,015(67.9 \%)$ & $15,053(58.3 \%)$ & $8026(26.7 \%)$ & $3909(26.0 \%)$ & $+0.8(-0.1,1.6)$ \\
\hline Beta-Blocker & $11,255(25.5 \%)$ & $4744(18.4 \%)$ & $3145(27.9 \%)$ & $1412(29.8 \%)$ & $-1.8(-3.4,-0.3)$ \\
\hline ACE inhibitor & $9211(20.8 \%)$ & $3463(13.4 \%)$ & $2030(22.0 \%)$ & $911(26.3 \%)$ & $-4.3(-6.0,-2.6)$ \\
\hline DHP CCB & $9943(22.5 \%)$ & $5789(22.4 \%)$ & $2323(23.4 \%)$ & $1260(21.8 \%)$ & $+1.6(0.3,3.0)$ \\
\hline ARB & $4969(11.2 \%)$ & $1566(6.1 \%)$ & $1094(22.0 \%)$ & $354(22.6 \%)$ & $-0.6(-3.0,1.8)$ \\
\hline Thiazide diuretic & $8769(19.8 \%)$ & $3820(14.8 \%)$ & $1402(16.0 \%)$ & $586(15.3 \%)$ & $+0.7(-0.7,2.0)$ \\
\hline Oral anti-diabetic & $9082(20.5 \%)$ & $4580(17.7 \%)$ & $2117(23.3 \%)$ & $1024(22.4 \%)$ & $+1.0(-0.5,2.4)$ \\
\hline Sulfonylurea & $4985(11.3 \%)$ & $2604(10.1 \%)$ & $1086(21.8 \%)$ & $535(20.5 \%)$ & $+1.2(-0.7,3.2)$ \\
\hline Biguanide & $5015(11.3 \%)$ & $1938(7.5 \%)$ & $1003(20.0 \%)$ & $419(21.6 \%)$ & $-1.6(-3.8,0.5)$ \\
\hline Antiplatelet & $4040(9.1 \%)$ & $2828(11.0 \%)$ & $897(22.2 \%)$ & $671(23.7 \%)$ & $-1.5(-3.6,0.5)$ \\
\hline Anti-dementia & $3861(8.7 \%)$ & $7761(30.1 \%)$ & $1288(33.4 \%)$ & $2121(27.3 \%)$ & $+6.0(4.2,7.8)$ \\
\hline Anti-osteoporotic & $3309(7.5 \%)$ & $2370(9.2 \%)$ & $438(13.2 \%)$ & $364(15.4 \%)$ & $-2.1(-4.0,-0.3)$ \\
\hline Proton pump inhibitor & $17,480(39.5 \%)$ & $10,213(39.6 \%)$ & $4186(23.9 \%)$ & $2634(25.8 \%)$ & $-1.8(-2.9,-0.8)$ \\
\hline At least one limited benefit medication & $44,218(100.0 \%)$ & $25,817(100.0 \%)$ & $13,191(29.8 \%)$ & $7862(30.5 \%)$ & $-0.7(-1.5,0.1)$ \\
\hline
\end{tabular}

ACE angiotensin-converting enzyme, ARB angiotensin receptor blocker, DHP CCB dihydropyridine calcium channel blocker, CI confidence interval *Patients with at least one dispensing for the class of interest through the Part D benefit after hospice admission among those with active use of that class in the 6 months prior to hospice admission

${ }^{\dagger}$ Difference in proportion of pre-hospice admission users with at least one Part D dispensing for the class of interest after hospice admission

${ }^{*}$ Selected drug classes only; results by therapeutic class include all associated drug classes in Table 1

Compared to patients using only one class prior to admission, the risk of continuing at least one limited benefit medication class after admission was 1.39 (95\% CI 1.35-1.44) among those using two limited benefit drug classes prior to admission and 2.00 (95\% CI 1.93-2.08) in those using six or more classes prior to admission (Table 4).

\section{DISCUSSION}

This is the first study to evaluate the continuation of limited benefit medications after admission to hospice. We accomplished this by identifying a cohort of patients with limited benefit medication use prior to hospice enrollment and following them through their hospice stay until death to assess continued dispensing of these medications through the Medicare Part D benefit. Among 70,035 Medicare beneficiaries who died in hospice and had active use of at least one limited benefit medication prior to hospice admission, $29.8 \%$ of patients admitted to hospice for a cancer diagnosis and $30.5 \%$ of those admitted for a non-cancer diagnosis continued to receive at least one of these medications after hospice enrollment. Continuation varied by medication class while factors such as age, hospice care setting, and length of hospice stay were independently associated with continuing one or more limited benefit medications after hospice admission.

Our results appear to align with current expert opinion and consensus surveys. Therapeutic classes more uniformly cited by geriatric and palliative care experts as providing minimal or no benefit at the end of life, such as anti-hyperlipidemic and antiosteoporotic medications, were generally continued less frequently than classes associated with a more uncertain benefit. ${ }^{25,40}$ If a medication has the potential to provide a symptomatic benefit, even if modest or only realized in a small proportion of total patients using the medication (e.g., oral anti-diabetics for treating symptomatic hyperglycemia), clinicians may elect to continue the medication as a conservative measure for the majority of their patients. This may help to explain the relatively frequent continuation of anti-dementia medications in our study, particularly among those admitted to hospice for cancer. While there is a growing consensus for anti-dementia medications' lack of benefit in terminal dementia, these medications could still be perceived to have therapeutic value in patients with terminal cancer (or other non-dementia terminal illnesses) where mild or moderate comorbid dementia is present. ${ }^{26,30,41}$

Recent studies have emerged which may help address the evidence gap concerning deprescribing outcomes in the hospice and palliative care setting. A large, epidemiologic study found that blood pressure values decreased progressively for the 14 to 18 years prior to death, with the steepest decreases among those dying at older ages and those being treated for hypertension; this may support a more judicious use of antihypertensive medications in the end of life setting. ${ }^{42} \mathrm{~A}$ randomized, controlled trial among patients with a life expectancy of 1 year or less found that statin discontinuation at the end of life was safe and did not diminish quality of life. ${ }^{43}$ In a small, interventional trial among frail older adults (mean age $=$ 84.3 years), patients discontinuing inappropriate medications and medications with no further symptomatic benefit did not experience an increase in mortality or reduction in quality of life after 12 months of follow-up. ${ }^{44}$ 
Table 4 Factors Associated with Continuation of $\geq 1$ Limited Benefit Medication After Hospice Admission

\begin{tabular}{|c|c|c|c|c|c|}
\hline \multirow[t]{3}{*}{ Variable } & \multirow{2}{*}{\multicolumn{2}{|c|}{$\begin{array}{l}\geq 1 \text { limited benefit } \\
\text { medication after } \\
\text { hospice admission }\end{array}$}} & \multicolumn{3}{|l|}{ Adjusted association } \\
\hline & & & \multirow{2}{*}{$\begin{array}{l}\text { All patients } \\
\text { RR (95\% CI) }\end{array}$} & \multirow{2}{*}{$\begin{array}{l}\begin{array}{l}\text { Cancer admission } \\
\text { diagnosis }\end{array} \\
\operatorname{RR}(95 \% \mathrm{CI})\end{array}$} & \multirow{2}{*}{$\begin{array}{l}\begin{array}{l}\text { Non-cancer admission } \\
\text { diagnosis }\end{array} \\
\text { RR }(95 \% \mathrm{CI})\end{array}$} \\
\hline & $n / N$ & $\%$ & & & \\
\hline \multicolumn{6}{|l|}{ Sex } \\
\hline Male & $6198 / 22,883$ & 27.1 & Ref* & Ref* & Ref* \\
\hline Female & $14,855 / 47,152$ & 31.5 & $1.01(0.99-1.03)$ & $1.02(0.99-1.05)$ & $0.99(0.96-1.02)$ \\
\hline \multicolumn{6}{|l|}{ Age (years) } \\
\hline $66-69$ & $1553 / 6117$ & 25.4 & $\operatorname{Ref}^{\dagger}$ & $\operatorname{Ref}^{\dagger}$ & $\operatorname{Ref}^{\dagger}$ \\
\hline $70-74$ & $2807 / 10,580$ & 26.5 & $1.04(0.99-1.08)$ & $1.05(1.00-1.10)$ & $1.00(0.90-1.10)$ \\
\hline $75-79$ & $3393 / 12,010$ & 28.3 & $1.06(1.02-1.10)$ & $1.08(1.03-1.13)$ & $1.00(0.91-1.09)$ \\
\hline $80-84$ & $4379 / 14,196$ & 30.9 & $1.11(1.07-1.16)$ & $1.13(1.08-1.18)$ & $1.01(0.92-1.10)$ \\
\hline $85-89$ & $4537 / 13,972$ & 32.5 & $1.14(1.10-1.18)$ & $1.17(1.12-1.22)$ & $0.99(0.91-1.08)$ \\
\hline$\geq 90$ & $4381 / 13,160$ & 33.3 & $1.17(1.13-1.22)$ & $1.19(1.14-1.25)$ & $0.99(0.91-1.08)$ \\
\hline \multicolumn{6}{|c|}{ 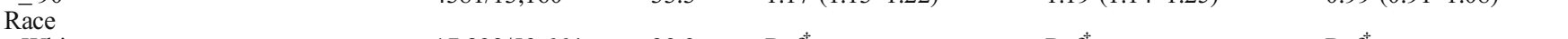 } \\
\hline White & $17,832 / 59,664$ & 29.9 & $\operatorname{Ref}^{\star}$ & $\operatorname{Ref}^{\star}$ & $\operatorname{Ref}^{*}$ \\
\hline Black & $1,955 / 5825$ & 33.6 & $0.97(0.94-1.01)$ & $0.98(0.94-1.03)$ & $0.95(0.90-1.01)$ \\
\hline Asian & $568 / 1996$ & 28.5 & $0.85(0.80-0.91)$ & $0.81(0.75-0.88)$ & $0.95(0.95-1.07)$ \\
\hline Hispanic & $393 / 1374$ & 28.6 & $0.88(0.82-0.94)$ & $0.86(0.79-0.93)$ & $0.89(0.80-0.99)$ \\
\hline \multicolumn{6}{|l|}{ Hospice admission setting } \\
\hline Private home & $12,992 / 40,241$ & 32.3 & $\operatorname{Ref}^{\S}$ & $\operatorname{Ref}^{\S}$ & $\operatorname{Ref}^{\S}$ \\
\hline Assisted living facility & $1496 / 3103$ & 48.2 & $1.28(1.24-1.32)$ & $1.24(1.18-1.30)$ & $1.28(1.22-1.34)$ \\
\hline Non-skilled nursing facility & $3812 / 8601$ & 44.3 & $1.29(1.25-1.32)$ & $1.35(1.30-1.40)$ & $1.26(1.21-1.32)$ \\
\hline Skilled nursing facility & $2012 / 5778$ & 34.8 & $1.25(1.20-1.29)$ & $1.29(1.23-1.36)$ & $1.21(1.15-1.27)$ \\
\hline Inpatient (acute care) hospital & $239 / 5718$ & 4.2 & $0.45(0.40-0.51)$ & $0.49(0.42-0.56)$ & $0.38(0.31-0.47)$ \\
\hline Inpatient hospice facility & $345 / 5655$ & 6.1 & $0.46(0.40-0.52)$ & $0.51(0.44-0.60)$ & $0.35(0.29-0.43)$ \\
\hline \multicolumn{6}{|l|}{ Primary hospice admission diagnosis } \\
\hline Cancer & $13,191 / 44,218$ & 29.8 & $\operatorname{Ref}^{\|}$ & & \\
\hline Debility or adult failure to thrive & $2190 / 5757$ & 38.0 & $1.05(1.02-1.09)$ & & \\
\hline Dementia & $2025 / 5425$ & 37.3 & $1.06(1.03-1.10)$ & & \\
\hline Lung disease & $1024 / 3568$ & 28.7 & $1.11(1.07-1.16)$ & & \\
\hline Heart disease & $1286 / 4368$ & 29.4 & $0.97(0.93-1.01)$ & & \\
\hline Ischemic stroke & $244 / 1389$ & 17.6 & $0.89(0.81-0.98)$ & & \\
\hline Renal disease & $253 / 1512$ & 16.7 & $1.03(0.94-1.13)$ & & \\
\hline Other non-cancer & $840 / 3798$ & 22.2 & $0.98(0.93-1.03)$ & & \\
\hline \multicolumn{6}{|l|}{ Hospice length of stay (days) } \\
\hline$\leq 7$ & $1122 / 23,339$ & 4.8 & $\operatorname{Ref}^{\mathrm{fl}}$ & $\operatorname{Ref}^{\mathrm{gl}}$ & $\operatorname{Ref}^{\mathrm{gI}}$ \\
\hline $8-14$ & $1498 / 10,994$ & 13.6 & $2.59(2.41-2.79)$ & $2.43(2.22-2.66)$ & $2.93(2.61-3.30)$ \\
\hline $15-29$ & $3072 / 11,155$ & 27.5 & $4.95(4.62-5.30)$ & $4.60(4.21-5.02)$ & $5.85(5.26-6.51)$ \\
\hline $30-89$ & $7686 / 14,347$ & 53.6 & $9.39(8.80-10.02)$ & $8.82(8.11-9.59)$ & $10.87(9.86-11.98)$ \\
\hline $90-179$ & $4033 / 5650$ & 71.4 & $12.11(11.33-12.95)$ & $11.81(10.85-12.86)$ & $12.92(11.69-14.29)$ \\
\hline$\geq 180$ & $3642 / 4550$ & 80.0 & $13.11(12.25-14.02)$ & $12.86(11.79-14.03)$ & $14.04(12.71-15.51)$ \\
\hline \multicolumn{6}{|c|}{ Number of outpatient clinicians in year prior to admission } \\
\hline $1-3$ & $6735 / 20,253$ & 33.3 & $\operatorname{Ref}^{\|}$ & Ref $^{\|}$ & $\operatorname{Ref}^{\|}$ \\
\hline $4-6$ & $7170 / 23,122$ & 31.0 & $0.99(0.96-1.01)$ & $0.97(0.95-1.00)$ & $0.99(0.96-1.03)$ \\
\hline $7-9$ & $4352 / 15,353$ & 28.4 & $0.96(0.94-0.98)$ & $0.95(0.92-0.98)$ & $0.97(0.93-1.01)$ \\
\hline$\geq 10$ & $2796 / 11,307$ & 24.7 & $0.91(0.89-0.94)$ & $0.90(0.86-0.93)$ & $0.95(0.90-1.00)$ \\
\hline \multicolumn{6}{|c|}{ Unique Part D medications in year prior to admission } \\
\hline $1-4$ & $399 / 1628$ & 24.5 & $\operatorname{Ref}^{\#}$ & $\operatorname{Ref}^{\#}$ & $\operatorname{Ref}^{\#}$ \\
\hline $5-9$ & $3330 / 11,769$ & 28.3 & $1.08(1.01-1.16)$ & $1.09(0.99-1.19)$ & $1.07(0.96-1.20)$ \\
\hline $10-19$ & $11,514 / 38,072$ & 30.2 & $1.11(1.03-1.18)$ & $1.10(1.01-1.20)$ & $1.14(1.02-1.28)$ \\
\hline $20-29$ & $4859 / 15,716$ & 30.9 & $1.13(1.06-1.22)$ & $1.12(1.02-1.22)$ & $1.20(1.07-1.34)$ \\
\hline$\geq 30$ & $951 / 2850$ & 33.4 & $1.18(1.09-1.28)$ & $1.13(1.02-1.25)$ & $1.33(1.16-1.51)$ \\
\hline \multicolumn{6}{|c|}{ Limited benefit drug classes used in 6 months prior to admission } \\
\hline 1 & $4128 / 20,591$ & 20.1 & $\operatorname{Ref} * *$ & Ref** & Ref** \\
\hline 2 & $5398 / 18,817$ & 28.7 & $1.39(1.35-1.44)$ & $1.41(1.36-1.47)$ & $1.37(1.31-1.43)$ \\
\hline 3 & $4868 / 14,260$ & 34.1 & $1.61(1.56-1.66)$ & $1.64(1.57-1.70)$ & $1.57(1.50-1.65)$ \\
\hline $4-5$ & $5158 / 13,035$ & 39.6 & $1.81(1.75-1.86)$ & $1.86(1.79-1.94)$ & $1.71(1.64-1.79)$ \\
\hline$\geq 6$ & $1501 / 3332$ & 45.1 & $2.00(1.93-2.08)$ & $2.08(1.98-2.18)$ & $1.87(1.76-1.98)$ \\
\hline
\end{tabular}

$n$ number of patients in stratum using at least one limited benefit medication after hospice admission, $N$ total number of patients in stratum, RR relative risk, CI confidence interval

*Adjusted for age, race, and hospice length of stay

${ }^{+}$Adjusted for sex, race, hospice length of stay, Part D low-income subsidy, and limited benefit medication classes used prior to hospice admission

${ }^{*}$ Adjusted for age, sex, hospice length of stay, and Part D low-income subsidy

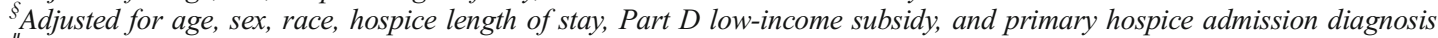

"Adjusted for age, sex, race, and hospice length of stay

"Adjusted for age, sex, race, hospice length of stay, Part D low-income subsidy, limited benefit medication classes used prior to hospice, hospice admission setting, and hospital discharge to hospice

${ }^{\#}$ Adjusted for age, sex, race, hospice length of stay, Part D low-income subsidy, limited benefit medication classes used prior to hospice, heart failure diagnosis, and COPD diagnosis

**Adjusted for age, sex, race, hospice length of stay, and Part D low-income subsidy 
The increased risk of continuation with hospice admission in nursing and assisted living facilities may have a basis in the prescription processing practices of long-term care pharmacies associated with these facilities. Given that initiation of hospice care in these settings often does not represent a change in where a patient is receiving care, standing orders for nonpalliative medications used prior to hospice enrollment may continue to be automatically dispensed by the facilityassociated pharmacy after a patient's hospice election. ${ }^{45}$ Explanations for higher rates of limited benefit medication continuation with increasing hospice length of stay are not immediately clear. Prescribers may be more likely to discontinue such medications in patients with a poorer prognosis and shorter anticipated life expectancy. ${ }^{46}$ Alternatively, this result may reflect the increased likelihood of receiving a prescription refill as patient survival, and therefore, time since the last medication fill, also increases. Further research is needed elucidating the patterns of medication discontinuation at the point of hospice admission and the mechanisms by which medications that are characterized by a lack of utility for symptom management are continued. Until then, periodic reviews of non-palliative medication use after hospice admission are warranted to ensure that patients' medication regimens continue to appropriately align with their goals of care.

\section{Limitations}

This study has several limitations. First and most importantly, the medication classes and disease-specific exclusions chosen for this study are exploratory and largely based on expert opinion. Thus, it is not intended to be a definitive or complete representation of non-essential medications in the hospice population, an area that is in great need of further research. Given the complexity of individual patient treatment decisions at the end of life, this approach and that of others should not be interpreted as a substitute for clinical judgement. Second, potentially influential factors such as hospice profit status and staffing levels, hospice program age, patient and family treatment preferences or perceived treatment benefits, level of cognitive and functional impairment, and family support were unable to be measured. Third, the true prevalence of medication continuation is likely underestimated as continuation was measured via new Part D dispensings after hospice admission. Patients without a new Part D dispensing may have continued using medication supplies obtained prior to admission during their hospice stay or obtained medication refills outside of their Part D plan. Certain medications with questionable palliative benefit may nevertheless have been provided by the patient's hospice program as related to palliation of the patient's terminal illness, resulting in outcome misclassification and further underestimation of continuation. Fourth, medication dispensing via claims is an imperfect proxy for medication use, particularly in the terminally ill population. Fifth, this study took place largely before the Medicare program began issuing guidance on Part D reimbursement in hospice, and clinicians may now be more cognizant of non-essential medication use in patients enrolled in hospice care.

\section{CONCLUSIONS}

Among Medicare beneficiaries who were admitted to and subsequently died in hospice, approximately $30 \%$ continued to receive medications which may have limited use in the palliation of terminal illness symptoms or quality of life improvement. Providers caring for patients admitted to hospice, particularly those admitted to hospice in nursing or assisted living facilities and those with a substantial non-palliative medication burden at admission, should carefully consider the burden versus benefit of medication continuation given the expectation of limited life expectancy. Our results highlight the need for the development of interventions targeting the discontinuation of limited benefit medications at the point of hospice enrollment.

Acknowledgments: This study used the linked SEER-Medicare database. The interpretation and reporting of these data are the sole responsibility of the authors. The collection of cancer incidence data used in this study was supported by the California Department of Public Health as part of the statewide cancer reporting program mandated by California Health and Safety Code Section 103885; the National Cancer Institute's Surveillance, Epidemiology and End Results Program under contract HHSN261201000140C awarded to the Cancer Prevention Institute of California, contract HHSN261201000035C awarded to the University of Southern California, and contract HHSN261201000034C awarded to the Public Health Institute; and the Centers for Disease Control and Prevention's National Program of Cancer Registries, under agreement no. U58DP003862-01 awarded to the California Department of Public Health. The ideas and opinions expressed herein are those of the author(s) and endorsement by the State of California Department of Public Health, the National Cancer Institute, and the Centers for Disease Control and Prevention or their Contractors and Subcontractors is not intended nor should be inferred. The authors acknowledge the efforts of the National Cancer Institute; the Office of Research, Development and Information, CMS; Information Management Services (IMS), Inc.; and the Surveillance, Epidemiology, and End Results (SEER) Program tumor registries in the creation of the SEER-Medicare database.

Corresponding Author: Todd A. Lee, PharmD, PhD; Department of Pharmacy Systems, Outcomes and PolicyUniversity of Illinois at Chicago, Chicago, IL, USA (e-mail: toddlee@uic.edu).

Funding Information PMZ was supported by a Dean's Scholar fellowship and Paul D. Doolen Scholarship for the Study of Aging through the University of Illinois at Chicago.

Data Availability The SEER-Medicare data that support the findings of this study are available from the National Cancer Institute, but restrictions apply to the availability of these data, which were used under license for the current study, and so are not publicly available.

\section{Compliance with Ethical Standards:}

The institutional review board at the University of Illinois at Chicago approved this study. Informed consent was not obtained as this study was determined by the institutional review board to not constitute human subjects research.

Conflict of Interest: PMZ was a doctoral candidate in the Department of Pharmacy Systems, Outcomes and Policy at the University of Illinois at Chicago when the study was conducted and is a current employee of AbbVie Inc. All remaining authors declare that they do not have a conflict of interest. 


\section{REFERENCES}

1. NHPCO Facts and Figures: Hospice Care in America. Alexandria, VA: National Hospice and Palliative Care Organization. . 2018; Available from: https://www.nhpco.org/sites/default/files/public/Statistics_Research/ 2017_Facts_Figures.pdf. Accessed 14 January 2019.

2. Tudor $\mathbf{C}$, Wilson $\mathbf{L}$, Majestic $\mathbf{M}$. Part D Payment for Drugs for Beneficiaries Enrolled in Hospice-Request for Comments [Memorandum]. Baltimore, MD: Centers for Medicare and Medicaid Services; 2013.

3. Sera L, McPherson ML, Holmes HM. Commonly Prescribed Medications in a Population of Hospice Patients. Am $\mathrm{J}$ Hosp Palliat Care 2014;31(2):126-31.

4. Sera L, Holmes HM, McPherson ML. Prescribing practices in hospice patients with adult failure to thrive or debility. Prog Palliat Care 2014;22(2):69-74.

5. Dwyer LL, Lau DT, Shega JW. Medications That Older Adults in Hospice Care in the United States Take, 2007. J Am Geriatr Soc 2015;63(11):2282-9.

6. Morin $\mathbf{L}$, Vetrano $\mathbf{D L}$, Rizzuto $\mathbf{D}$, Calderón-Larrañaga A, Fastbom $\mathbf{J}$, Johnell K. Choosing Wisely? Measuring the Burden of Medications in Older Adults near the End of Life: Nationwide, Longitudinal Cohort Study. Am J Med 2017;130(8):927-936.e9.

7. Lunney JR, Lynn J, Foley DJ, Lipson S, Guralnik JM. Patterns of functional decline at the end of life. JAMA 2003;289(18):2387-92.

8. McNeil MJ, Kamal AH, Kutner JS, Ritchie CS, Abernethy AP. The Burden of Polypharmacy in Patients Near the End of Life. J Pain Symptom Manag 2016;51(2):178-183.e2.

9. LeBlanc TW, McNeil MJ, Kamal AH, Currow DC, Abernethy AP. Polypharmacy in patients with advanced cancer and the role of medication discontinuation. Lancet Oncol 2015;16(7):e333-41.

10. Maddison AR, Fisher J, Johnston G. Preventive medication use among persons with limited life expectancy. Prog Palliat Care 2011;19(1):15-21.

11. Domingues D, Carneiro R, Costa I, et al. Therapeutic futility in cancer patients at the time of palliative care transition: An analysis with a modified version of the Medication Appropriateness Index. Palliat Med 2015;29(7):643-51.

12. Alexander GC, Sayla MA, Holmes HM, Sachs GA. Prioritizing and stopping prescription medicines. Can Med Assoc J 2006;174(8):1083-4.

13. Lau DT, Joyce B, Clayman ML, et al. Hospice Providers' Key Approaches to Support Informal Caregivers in Managing Medications for Patients in Private Residences. J Pain Symptom Manag 2012;43(6):1060-71.

14. Holmes H. Rational Prescribing for Patients With a Reduced Life Expectancy. Clin Pharmacol Ther 2009;85(1):103-7.

15. Todd A, Holmes HM. Recommendations to support deprescribing medications late in life. Int J Clin Pharm 2015;37(5):678-81.

16. Nordennen R, Lavrijsen J, Vissers K, Koopmans R. Decision Making About Change of Medication for Comorbid Disease at the End of Life: An Integrative Review. Drugs Aging 2014;31(7):501-12.

17. Lee SP, Bain KT, Maio V. Appropriate Discontinuation of Medications at the End of Life: A Need to Establish Consensus Criteria. Am J Med Qual 2007;22(6):393-4

18. Fede A, Miranda $\mathbf{M}$, Antonangelo $\mathbf{D}$, et al. Use of unnecessary medications by patients with advanced cancer: cross-sectional survey. Support Care Cancer 2010;19(9):1313-8.

19. Bain KT, Holmes HM, Beers MH, Maio V, Handler SM, Pauker SG Discontinuing Medications: A Novel Approach for Revising the Prescribing Stage of the Medication-Use Process. J Am Geriatr Soc 2008;56(10): 1946-52.

20. Mullvain JA, Kozak KR, Moody JS, Campbell TC. Statin use in cancer patients with brain metastases: a missed communication opportunity at the end of life. Support Care Cancer 2015;23(9):2643-8.

21. Kruser JM, Cox CE, Schwarze ML. Clinical Momentum in the Intensive Care Unit. A Latent Contributor to Unwanted Care. Ann Am Thorac Soc 2017;14(3):426-31.

22. Bayliss EA, Bronsert MR, Reifler LM, et al. Statin Prescribing Patterns in a Cohort of Cancer Patients with Poor Prognosis. J Palliat Med 2013;16(4):412-8.

23. Zueger PM, Holmes HM, Calip GS, Qato DM, Pickard AS, Lee TA Medicare Part D Use of Older Medicare Beneficiaries Admitted to Hospice. J Am Geriatr Soc 2018;66(5):937-44.

24. Centers for Medicare and Medicaid Services. Medicare Hospice Data Trends: 1998-2009 [Data File]. 2012. Available from: https://www.cms. gov/Medicare/Medicare-Fee-for-Service-Payment/Hospice/Medicare Hospice_Data.html. Accessed 14 January 2019.
25. Lavan AH, Gallagher P, Parsons C, O'Mahony D. STOPPFrail (Screening Tool of Older Persons Prescriptions in Frail adults with limited life expectancy): consensus validation. Age Ageing 2017;46(4):600-7.

26. Holmes HM, Sachs GA, Shega JW, Hougham GW, Cox Hayley D, Dale W. Integrating Palliative Medicine into the Care of Persons with Advanced Dementia: Identifying Appropriate Medication Use. J Am Geriatr Soc 2008;56(7): 1306-11

27. Riechelmann RP, Krzyzanowska MK, Zimmermann C. Futile medication use in terminally ill cancer patients. Support Care Cancer 2008;17(6):745-8.

28. Dewhurst F, Baker L, Andrew I, Todd A. Blood pressure evaluation and review of antihypertensive medication in patients with life limiting illness. Int J Clin Pharm 2016;1-4.

29. Lindsay $\mathbf{J}$, Dooley M, Martin $\mathbf{J}$, et al. The development and evaluation of an oncological palliative care deprescribing guideline: the 'OncPal deprescribing guideline.' Support Care Cancer 2014;23(1):71-8.

30. Shega JW, Ellner L, Lau DT, Maxwell TL. Cholinesterase Inhibitor and N-Methyl-D-Aspartic Acid Receptor Antagonist Use in Older Adults with End-Stage Dementia: A Survey of Hospice Medical Directors. J Palliat Med 2009;12(9):779-83.

31. Raijmakers NJH, van Zuylen L, Furst CJ, et al. Variation in medication use in cancer patients at the end of life: a cross-sectional analysis. Support Care Cancer 2013;21(4):1003-11.

32. Todd A, Nazar H, Pearson S, Andrew I, Baker L, Husband A Inappropriate prescribing in patients accessing specialist palliative day care services. Int J Clin Pharm 2014;36(3):535-43.

33. Todd A, Husband A, Andrew I, Pearson S-A, Lindsey L, Holmes H. Inappropriate prescribing of preventative medication in patients with lifelimiting illness: a systematic review. BMJ Support Palliat Care 2017;7(2):113-21.

34. Cruz-Jentoft AJ, Boland B, Rexach L. Drug Therapy Optimization at the End of Life. Drugs Aging 2012;29(6):511-21.

35. Kröger E, Wilchesky M, Marcotte M, et al. Medication Use Among Nursing Home Residents With Severe Dementia: Identifying Categories of Appropriateness and Elements of a Successful Intervention. J Am Med Dir Assoc 2015; 16(7):629.e1-17.

36. Yelland LN, Salter AB, Ryan P. Performance of the modified Poisson regression approach for estimating relative risks from clustered prospective data. Am J Epidemiol 2011;174(8):984-92.

37. Zou G, Donner A. Extension of the modified Poisson regression model to prospective studies with correlated binary data. Stat Methods Med Res 2013;22(6):661-70.

38. Westreich D, Greenland S. The Table 2 Fallacy: Presenting and Interpreting Confounder and Modifier Coefficients. Am J Epidemiol 2013; 177(4):292-8.

39. Lee $\mathbf{P H}$. Is a Cutoff of $10 \%$ Appropriate for the Change-in-Estimate Criterion of Confounder Identification? J Epidemiol 2014;24(2):161-7.

40. Morin L, Laroche M-L, Vetrano DL, Fastbom J, Johnell K. Adequate, questionable, and inadequate drug prescribing for older adults at the end of life: a European expert consensus. Eur J Clin Pharmacol 2018;1-10.

41. Parsons C. Withdrawal of Antidementia Drugs in Older People: Who, When and How? Drugs Aging 2016;33(8):545-56.

42. Delgado J, Bowman K, Ble A, et al. Blood Pressure Trajectories in the 20 Years Before Death. JAMA Intern Med 2018;178(1):93-9.

43. Kutner JS, Blatchford PJ, Taylor DH, et al. Safety and Benefit of Discontinuing Statin Therapy in the Setting of Advanced, Life-Limiting Illness. JAMA Intern Med 2015;175(5):691-700.

44. Potter K, Flicker L, Page A, Etherton-Beer C. Deprescribing in Frail Older People: A Randomised Controlled Trial. PLoS One 2016;11(3).

45. CMS Review of Current Standards of Practice for Long-Term Care Pharmacy Services. [Internet]. The Lewin Group; 2004. Available from: https://www.cms.gov/Research-Statistics-Data-and-Systems/Statistics-Trends-and-Reports/Reports/downloads/lewingroup.pdf. Accessed 14 January 2019

46. Chróinín DN, Chróinín CN, Beveridge A. Factors influencing deprescribing habits among geriatricians. Age Ageing 2015;44(4):704-8.

Publisher's Note Springer Nature remains neutral with regard to jurisdictional claims in published maps and institutional affiliations. 